\title{
latrogenic foreign body in urinary bladder: Holmium laser vs. Ceramic, and the winner is...
}

\author{
Daniele Castellani 1, Luca Gasparri 1, Redi Claudini 1, Maria Pia Pavia ${ }^{1}$, Alessandro Branchi ${ }^{1}$, Marco \\ Dellabella ${ }^{1}$ \\ ${ }^{1}$ Department of Urology, IRCCS-INRCA, Ancona, Italy
}

\section{ABSTRACT}

Introduction: Urological surgery is estimated to be the third most common cause of iatrogenic-retained foreign bodies (1). Presentation: A 76-year old man was undergoing a transurethral resection of bladder tumor with a 26-Ch continuous flow resectoscope (Karl Storz, Germany). Before starting resection, a detachment of resectoscope sheath tip was noted. The ceramic tip was free-floating in the bladder lumen, and it would not fit within the sheath, making direct extraction using the loop impossible. An attempt was made to break it with a stone punch, but it was unsuccessful due to impossibility of closing it in the branches. Therefore, we decided to fragment the tip with holmium laser (RevoLix ${ }^{\circledR}$, LISA Laser products, Germany), using an 800-micron, front-firing fiber. Laser device was settled at with $2.5 \mathrm{~J}$ energy and 5 Hz frequency. Ceramic appeared very hard, but it was difficult to carry on breaking with this setting because of tip retropulsion. Then, laser setting was switched to lower energy and higher frequency ( $1 \mathrm{~J}$ and $13 \mathrm{~Hz}$ ). This setting guaranteed the same power of $13 \mathrm{~W}$, but with minimal retropulsion.

Results: Tip was fragmented against the posterior bladder wall in seven pieces, which were retrieved trough the outer sheath. A total $5.62 \mathrm{~kJ}$ were used to fragment it. At the end, superficial lesions of the posterior bladder wall were highlighted. Surgical time was 55 minutes. Patient was discharged home next day without problems.

Conclusions: Holmium laser fragmentation is a safe and effective approach to remove foreign bodies from the bladder.

\section{ARTICLE INFO}

Available at: http://www.intbrazjurol.com.br/video-section/20180229_Castellani_et_al Int Braz J Urol. 2019; 45 (Video \#14): 853-853

\section{REFERENCES}

1. Lincourt AE, Harrell A, Cristiano J, Sechrist C, Kercher K, Heniford BT: Retained Foreign Bodies After Surgery. J Surg Res. 2007; 138:170-74.

Submitted for publication:

March 27, 2018

Accepted after revision:

December 04, 2018

Published as Ahead of Print:

February 10, 2019
Correspondence address:

Daniele Castellani, MD

Department of Urology, IRCCS-INRCA

Via della Montagnola 81, 60127 Ancona, Italy

Fax: +397 1800-3643

E-mail: d.castellani@inrca.it 